\title{
Clinical protection against caprine herpesvirus I genital infection by intranasal administration of a live attenuated glycoprotein $E$ negative bovine herpesvirus I vaccine
}

\author{
Julien Thiry ${ }^{1,2}$, Maria Tempesta ${ }^{1}$, Michele Camero ${ }^{1}$, Elvira Tarsitano1, \\ Benoît Muylkens ${ }^{2}$, François Meurens ${ }^{3}$, Etienne Thiry*2 and \\ Canio Buonavoglia ${ }^{1}$
}

\begin{abstract}
Address: ${ }^{1}$ Department of Animal Health and Well-being, Faculty of Veterinary Medicine, University of Bari, 70010 Valenzano, Italy, ${ }^{2}$ Department of Infectious and Parasitic Diseases, Virology and Viral Diseases, Faculty of Veterinary Medicine, University of Liège, 4000 Liège, Belgium and ${ }^{3}$ Lymphocyte et Immunité des Muqueuses, IASP 311, UR 1282, National Institute of Agronomy Research (INRA), 37380 Nouzilly, France

Email: Julien Thiry - julien.thiry@ulg.ac.be; Maria Tempesta - m.tempesta@veterinaria.uniba.it;

Michele Camero - m.camero@veterinaria.uniba.it; Elvira Tarsitano - e.tarsitano@veterinaria.uniba.it; Benoît Muylkens - bmuylkens@ulg.ac.be; François Meurens - meurens@tours.inra.fr; Etienne Thiry* - etienne.thiry@ulg.ac.be; Canio Buonavoglia - c.buonavoglia@veterinaria.uniba.it

* Corresponding author
\end{abstract}

Published: 5 December 2007

BMC Veterinary Research 2007, 3:33 doi:10.1186/1746-6/48-3-33

This article is available from: http://www.biomedcentral.com/I746-6/48/3/33

(C) 2007 Thiry et al; licensee BioMed Central Ltd.

This is an Open Access article distributed under the terms of the Creative Commons Attribution License (http://creativecommons.org/licenses/by/2.0), which permits unrestricted use, distribution, and reproduction in any medium, provided the original work is properly cited.
Received: 22 August 2007

Accepted: 5 December 2007

\begin{abstract}
Background: Caprine herpesvirus I (CpHV-I) is responsible of systemic diseases in kids and genital diseases leading to abortions in goats. CpHV-I is widespread and especially in Mediterranean countries as Greece, Italy and Spain. CpHV-I is antigenically and genetically closely related to bovine herpesvirus I (BoHV-I). Taking into account the biological properties shared by these two viruses, we decided in the current study to assess the protection of a live attenuated glycoprotein $\mathrm{E}(\mathrm{gE})$ negative BoHV-I vaccine against a genital $\mathrm{CpHV}-\mathrm{I}$ infection in goats.

Results: The vaccine was inoculated intranasally twice three weeks apart followed by a subsequent $\mathrm{CpHV}-\mathrm{I}$ intravaginal challenge which is the natural route of infection in three goats. To analyse the safety and the efficacy of this marker vaccine, two groups of three goats served as controls: one immunised with a virulent $\mathrm{CpHV}-\mathrm{I}$ and one uninoculated until the challenge. Goats were clinically monitored and all sampling procedures were carried out in a blind manner. The vaccine did not induce any undesirable local or systemic reaction and goats did not excrete gE-negative BoHV-I. After challenge, a significant reduction in disease severity was observed in immunised goats. Moreover, goats immunised with either gE-negative BoHV-I or CpHV-I exhibited a significant reduction in the length and the peak of viral excretion. Antibodies neutralising both BoHV-I and $\mathrm{CpHV}-\mathrm{I}$ were raised in immunised goats.
\end{abstract}

Conclusion: Intranasal application of a live attenuated gE-negative BoHV-I vaccine is able to afford a clinical protection and a reduction of virus excretion in goats challenged by a $\mathrm{CpHV}-\mathrm{I}$ genital infection. 


\section{Background}

The subfamily Alphaherpesvirinae includes a cluster of closely related ruminant viruses with bovine herpesvirus 1 (BoHV-1) as prototype [1]. BoHV-1, a major cattle pathogen, is typically responsible of infectious bovine rhinotracheitis (IBR) causing severe economic losses in livestock [2]. Since its isolation, several conventional vaccines have been developed. These vaccines usually prevented clinical signs and reduced the amount of excreted viruses. However, there was still a need for improvements in order to use them in control and/or eradication programmes [3]. Therefore, BoHV-1 marker vaccines comprising attenuated or killed mutants with a deletion in one of the nonessential genes ( $\mathrm{gE}$ ) were developed and eradication campaigns were initiated in many European countries. They have proven their safety and efficacy in the target bovine species since they are efficacious at reducing disease severity, virus shedding, and circulation in a population $[4,5]$.

Caprine herpesvirus 1 (CpHV-1) is associated with two different syndromes in goats, a lethal systemic disease in kids $[6,7]$ and a genital disease leading to balanoposthitis [8], vulvovaginitis [9] and abortion [10] in adults. These clinical signs and the virus presence in nasal, ocular, rectal and vaginal samples suggest both the venereal transmission as the principal virus entry route and infection persistence within herds $[11,12]$. The genital tropism of CpHV-1 was confirmed by the detection of viral DNA in sacral ganglia of latently infected goats [13]. According to serological investigations, the infection occurs worldwide with highest prevalences observed in Mediterranean countries [14-20]. However, the economical losses due to $\mathrm{CpHV}-1$ infection are probably underestimated. To date, a classical inactivated vaccine has been developed [21,22], however, it can not be licensed since the market of veterinary medicinal products for minor species, like goats, is not economically profitable. Consequently, the control of this infection still relies on hygienic prophylactic measures [1].

BoHV-1 and CpHV-1 are antigenically and genetically closely related [1]. This relationship was originally demonstrated by serological assays [15,23-25] and lately by phylogenetic analysis [26-28]. These viruses are able to some extent to cross the species barrier and establish infection in heterologous animal species [29,30]. Experimental reactivation of latent infection of BoHV-1 in goats was successfully performed [31]. Moreover, a recent experiment showed that intranasal administration of a live attenuated gE-negative BoHV-1 vaccine in goats reduced the peak viral titre after a nasal CpHV-1 challenge and therefore afforded a partial cross-protection [32].

In the following study, it is hypothesised that an intranasal administration (of a bovine vaccine) could afford a protection against the clinical genital infection. Indeed, for many years, the upper respiratory mucosa has been proven to be suitable for vaccine delivery. The recent advances in the study of the mucosal immune system strengthen this mode of administration as being a very effective route for vaccination for both peripheral and mucosal immunity [33]. In human, nasal mucosa can serve as an efficient site for the induction of specific IgA and IgG responses in vaginal secretions [34,35]. The goat genital tract might employ similar homing mechanisms as those of the upper respiratory tract and therefore could receive primed immune cells from the nasopharynx-associated lymphoid tissue (NALT) [36]. Therefore, it was decided to investigate gE-negative BoHV-1 intranasal route of vaccination in goats with the aim to protect this species against CpHV-1 genital infection.

\section{Results}

Clinical and viral responses after intranasal immunisation Goats immunised by intranasal inoculation with virulent CpHV-1 or gE-negative BoHV-1 vaccine remained in good general state of health. No signs of severe disease as anorexia, depression, oedema or lesions were observed. The gE-negative BoHV-1 immunisation did not induce any undesirable local or systemic reaction and goats did not show any clinical sign of disease. On the opposite, goats inoculated with CpHV-1 expressed mild clinical signs as hyperemia and nasal discharge. Based on the mean rectal temperature, the statistical analysis revealed significant differences between groups ( $\mathrm{p}<0.005)$. From day 3 after immunisation, the mean temperatures of $\mathrm{CpHV}-1$ inoculated goats were higher than the temperature of gE-negative BoHV-1 immunised goats $(\mathrm{p}<0.001)$ (data not shown).

Following the first immunisation (day 0), only CpHV-1 was excreted by goats (Fig. 1). CpHV-1 was isolated in cell culture and was detected by PCR in nasal swabs but was not recovered from vaginal swabs and buffy coats. The peak viral titre was $10^{6.6} \mathrm{TCID}_{50}$ per $50 \mu \mathrm{l}$ of nasal secretions. After the second immunisation (day 21), both samples from gE-negative BoHV-1 and from CpHV-1 infected goats were consistently negative by isolation in cell culture and detection by PCR.

\section{Viral excretion after $\mathbf{C p H V - I}$ intravaginal challenge}

Three weeks after the second immunisation, control and immunised goats were intravaginally challenged with the virulent CpHV-1 Ba-1 strain (Fig. 2). The mean CpHV-1 titres in vaginal swabs were significantly different $(\mathrm{p}<$ 0.0001 ) between groups immunised with either gE-negative BoHV-1 vaccine or virulent $\mathrm{CpHV}-1$ and the nonimmunised group. The lowest excretion titres were obtained in the CpHV-1 immunised group compared to gE-negative BoHV-1 immunised or non-immunised 


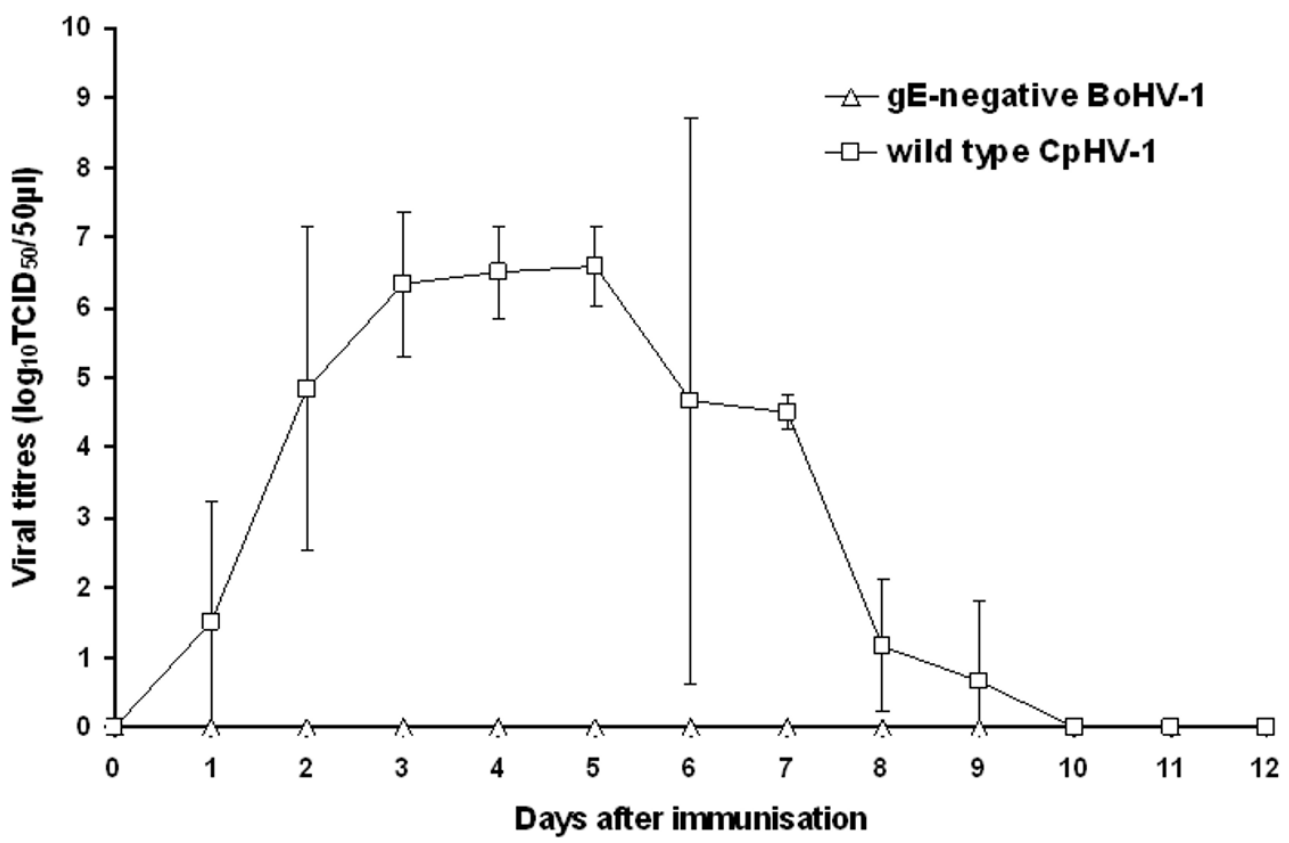

Figure I

Mean titres of BoHV-I or CpHV-I in nasal swabs recorded after intranasal immunisation of goats with either live attenuated gE-negative BoHV-I vaccine or virulent CpHV-I Ba-I. Titres are expressed as $\log _{10} \mathrm{TCID}_{50}$ Per $50 \mu \mathrm{l}$ of nasal secretions.

groups $(\mathrm{p}<0.0001)$. The immunisation with gE-negative BoHV-1 vaccine decreased the mean challenge virus excretion titres: $1.42 \log$ on day 2, $1.75 \log$ on day $3,1.5 \log$ on day $6,1.66 \log$ on day $7,2.75$ on day 8 , except on days 4 , 5 and 9 after challenge where the mean excretion titres, although not significantly different, were lower than the mean excretion titres obtained on the same day in nonimmunised goats. Furthermore, the gE-negative BoHV-1 vaccine shortened the challenge strain shedding. While no viral shedding was detected on day 12 in non-immunised group, goats from the gE-negative BoHV-1 immunised group excreted the challenge CpHV-1 during a significantly shorter time period. The shortest virus shedding, up to day 1 after challenge, was detected in the CpHV-1 immunised group (Fig. 2).

On days 1 and 4 after challenge, viruses from one goat in each group were further propagated individually and characterised using restriction enzyme analysis. The BstEII profiles confirmed that viruses excreted after challenge by goats immunised with gE-negative BoHV-1 vaccine were CpHV-1 challenge Ba-1 strain (data not shown).

Clinical protection against CpHV-I intravaginal challenge Groups intranasally immunised with either virulent CpHV-1 or gE-negative BoHV-1 vaccines were protected against the clinical form of the genital CpHV-1 infection
(Fig. 3). Consequently, the clinical score of each group was significantly lower $(\mathrm{p}<0.0001)$ than in the nonimmunised group. The statistical analysis revealed no significant difference between the gE-negative BoHV-1 immunised and the CpHV-1 immunised groups $(\mathrm{p}=$ 0.06 ) except at days 5 and 6 after challenge. At these days, goats immunised with gE-negative BoHV-1 vaccine showed mild oedema or vulva hyperemia.

The mean rectal temperature of immunised groups was significantly lower $(p<0.0001)$ than those of the nonimmunised group except at the challenge peak (days 3 and 5 after challenge). Additionally, the group immunised by inoculation with virulent CpHV-1 exhibited a significant lower temperature $(\mathrm{p}<0.0001)$ than the $\mathrm{gE}-$ negative BoHV-1 vaccine immunised group. Overall, goats did not show any sign of hyperthermia (data not shown).

\section{Immune responses after immunisation and challenge}

In goats immunised with either virulent CpHV-1 or gEnegative BoHV-1 vaccine, $\mathrm{CpHV}-1$ neutralising antibodies were observed from day 14 after the first immunisation (Fig. 4). No significant difference between groups was noticed. After the second immunisation, a sharp increase in CpHV-1 neutralising antibody titres was observed in the CpHV-1 immunised group. In contrast, goats immu- 


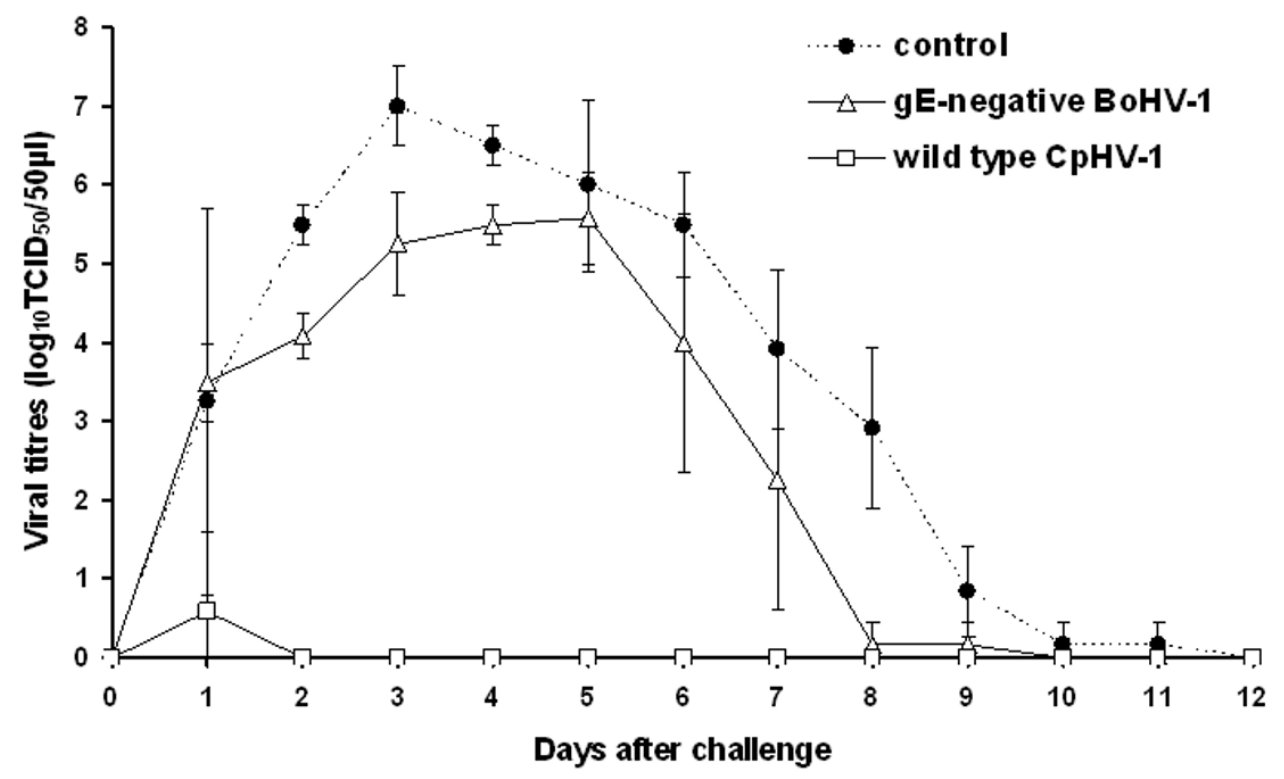

Figure 2

Mean titres of CpHV-I in vaginal swabs recorded after CpHV-I Ba-I intravaginal challenge of goats previously intranasally immunised with either live attenuated gE-negative BoHV-I vaccine or virulent CpHV-I Ba-I. The control group was not inoculated with any preparation. Titres are expressed as $\log _{10} \operatorname{TCID}_{50}$ per $50 \mu$ of vaginal secretions.

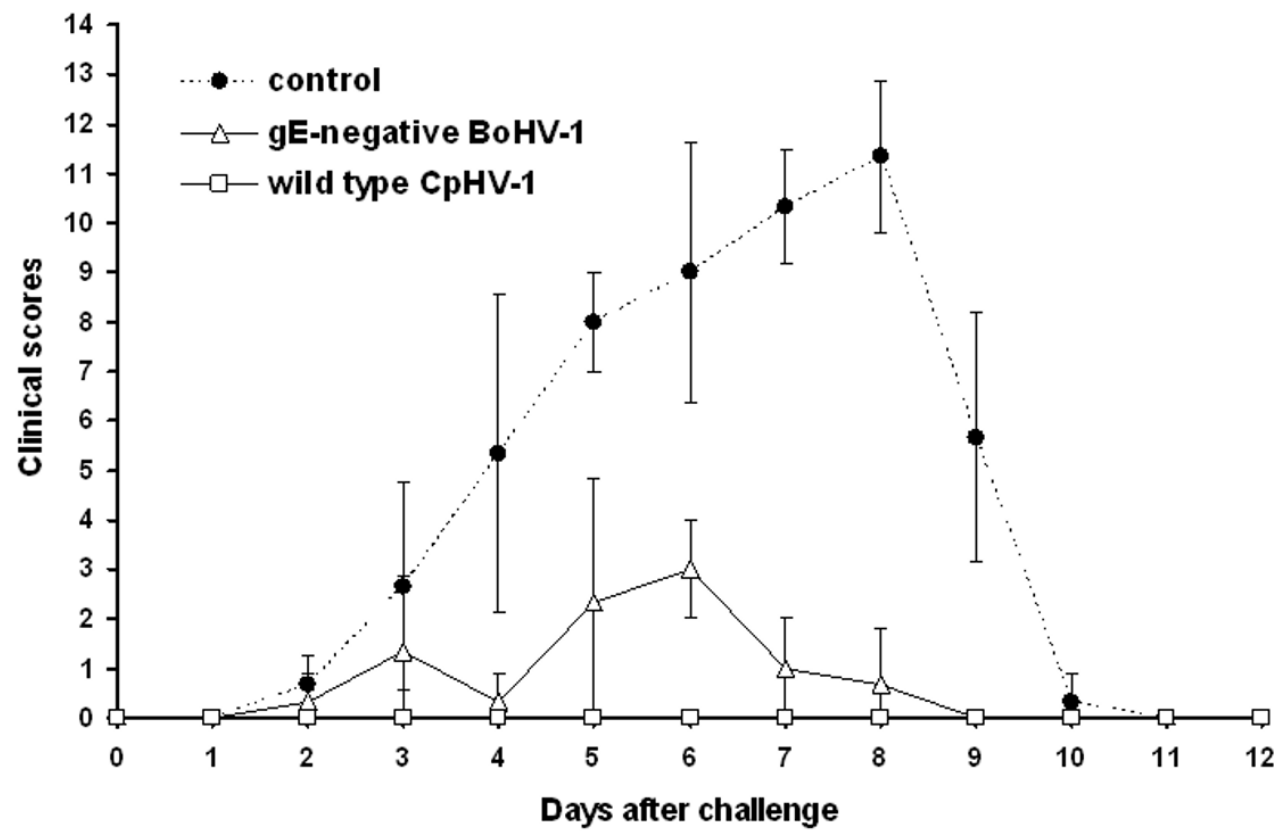

Figure 3

Mean clinical scores recorded after CpHV-I Ba-I intravaginal challenge of goats previously intranasally immunised with either live attenuated gE-negative BoHV-I vaccine or virulent CpHV-I Ba-I. The control group was not inoculated with any preparation. 


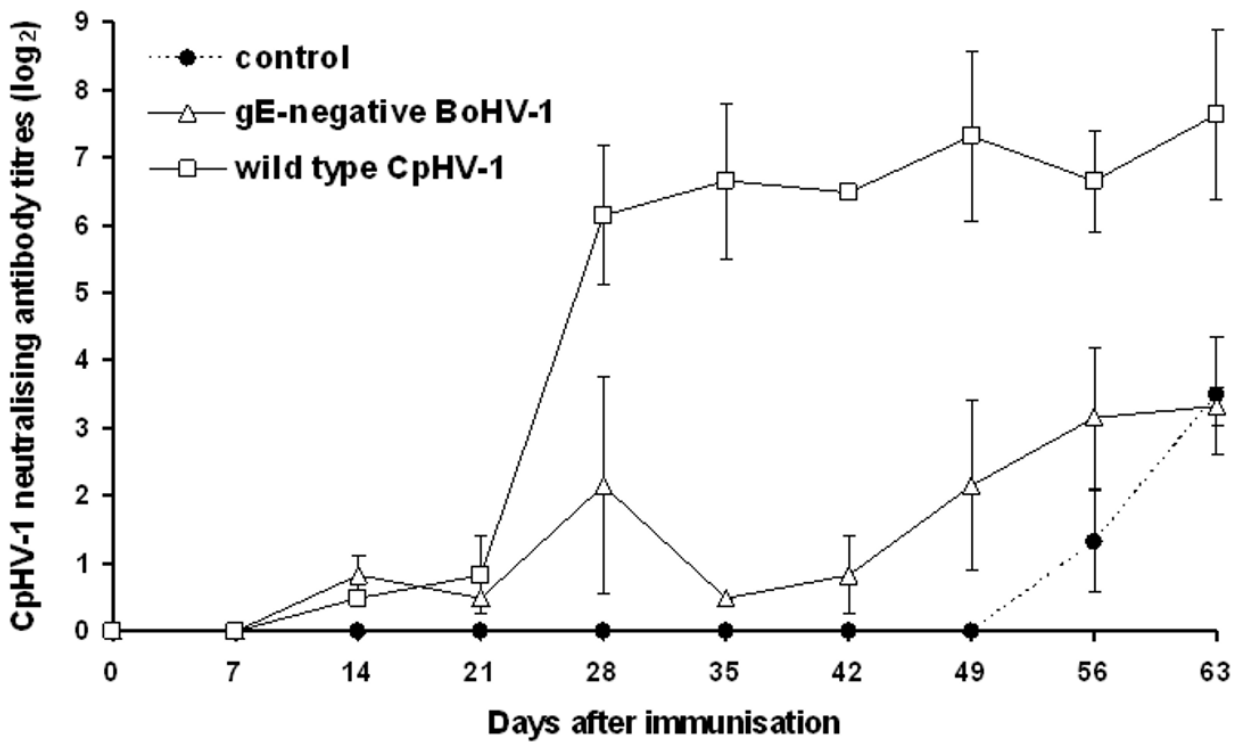

\section{Figure 4}

Evolution of $\mathrm{CpHV}$-I neutralising antibody titres in goats intranasally immunised on day 0 with either live attenuated gE-negative BoHV-I vaccine or virulent CpHV-I Ba-I. The control group was not inoculated with any preparation. Goats were intravaginally challenged with virulent $\mathrm{CpHV}-\mathrm{I} \mathrm{Ba}-\mathrm{I}$ on day 42 . Neutralising titres are expressed as the initial dilution of serum that neutralised $50 \%$ of wells, calculated using the Spearman-Kärber method.

nised with gE-negative BoHV-1 did not show any boost of the primary immune response (Fig. 4). Following the CpHV-1 intravaginal challenge, the mean CpHV-1 neutralising antibody titres were significantly different $(\mathrm{p}<$ 0.0001 ) between groups immunised with gE-negative BoHV-1 or CpHV-1 and the non-immunised group. Interestingly, goats immunised with gE-negative BoHV-1 vaccine showed an increase in CpHV-1 neutralising antibodies, but their neutralising titres were much lower than that of CpHV-1 immunised goats (Fig. 4). Neutralising antibody titres were lower against BoHV-1 than CpHV-1 in all groups (data not shown). Moreover, all animals remained negative with the BoHV-1 gE blocking ELISA.

\section{Discussion}

Taking advantage of the susceptibility of goats to BoHV-1 [32], the efficacy of a live attenuated gE-negative BoHV-1 vaccine was assessed in goats after two intranasal administrations followed by a subsequent $\mathrm{CpHV}-1$ intravaginal challenge. The intranasal use of a gE-negative BoHV-1 vaccine enabled a cross-protection against CpHV-1 genital infection which is the natural route of infection in goats. As observed in human, nasal mucosa can serve as an efficient site for the induction of a specific protective response in the genital tract. It could be a consequence of the induction of specific IgA and IgG responses in vaginal secretions. The presence of specific antibody secreting cells (ASCs) in the genital tract have been demonstrated after nasal vaccination in mice $[37,38]$. In another study, it has been shown that $\mathrm{T}$ lymphocyte homing to the genital mucosa requires the interaction of integrins $\alpha_{L} \beta_{2}$ and $\alpha_{4} \beta_{1}$ with endothelial intercellular adhesion molecule- 1 and vascular cell adhesion molecule-1 (VCAM-1), respectively $[39,40]$. Since both nasal and genital mucosa express VCAM-1, this adressin could be involved in the homing of specific ASCs to the genital tract. Moreover, chemokine like CC chemokine ligand 28, which is expressed in both tissues, could interact with the chemokine receptor 10 expressed on nasal ASCs and be involved too in the homing of specific ASCs to the genital area $[41,42]$. Although the underlying mechanism was not investigated in this study, it can be speculated that such pathways could be involved in the current protection.

Following the first immunisation, the safety of the gE-negative BoHV-1 vaccine in goats was evidenced by the absence of side effects and local or systemic reactions. Interestingly, goats did not excrete gE-negative BoHV-1 although a low level of BoHV-1 excretion was observed previously [32]. A weaker replication of gE-negative BoHV-1 could account for this result. Nevertheless, the presence of neutralising antibodies against BoHV-1 after the first and second immunisations suggests the replication of gE-negative BoHV-1 in goats. It can be hypothesised that the first immunisation induced a strong 
mucosal immunity leading to the neutralisation of newly replicated viruses after the second immunisation. The absence of detection of anti-gE antibodies in BoHV-1 gE blocking ELISA is consistent with the deletion of the gene encoding gE in the BoHV-1 vaccine. Moreover, such negative results in goats inoculated with $\mathrm{CpHV}-1$ suggest a difference in the antigenicity of gE between BoHV-1 and CpHV-1.

Another issue to consider is the possible establishment of gE-negative BoHV-1 in a latent state in vaccinated goats. Indeed, BoHV-1 is able to establish latency in goats but with a poor reactivation success rate [30,31]. However, gEnegative BoHV-1 is less effective in reactivation and reexcretion than wild type viruses in calves $[4,43]$. Therefore, the risk of reactivation and reexcretion of a gE-negative BoHV-1 in goats is low. On the other hand, the vaccination could also lead to the emergence of new recombinant viruses. Indeed, despite the fact that in the subfamily Alphaherpesvirinae, viruses of different species show very few sequence similarities to allow homologous recombination, several interspecific recombinants were isolated in vitro [44]. Natural recombinants between equid herpesviruses 1 and 4 were, for example, recently identified [45]. Therefore, the question of recombinants rising from crossinfection of CpHV-1 infected goats with BoHV-1 needs to be considered. Among the cluster of ruminant alphaherpesviruses related to BoHV-1, only two recombinant viruses between BoHV-1 and BoHV-5 were isolated, and no recombinant between BoHV-1 and less closely related CpHV-1 and CvHV-2 was detected in vitro [46]. Consequently, in regards of these data and especially the low level of excretion, the vaccination described here is likely to be completely safe.

The reduction of the clinical score was considered as the most relevant parameter showing the efficacy of nasal immunisation against CpHV-1. Goats immunised intranasally with gE-negative BoHV-1 vaccine were clinically protected. Moreover, the difference between goats immunised with either gE-negative BoHV-1 or CpHV-1 was not statistically significant. The gE-negative BoHV-1 vaccine was not only effective in preventing development of genital disease upon challenge, but also in significantly reducing the magnitude and the duration of challenge CpHV-1 excretion. A high protection against clinical signs was also observed after immunisation by intranasal infection with CpHV-1. However, in natural conditions, the same kind of protection is not likely to be reached because the main route of transmission is venereal instead of respiratory $[11,12]$. The current CpHV-1 vaginal challenge used in this assay was even more severe than in previous experiments $[47,48]$ and this result brings a reliable validation of the current study. The significant differences observed between immunised and non-immunised groups have been obtained with a relatively low number of animals, therefore despite a lower power of the statistical test. These data allowed the identification of a significant effect of vaccination with the live attenuated gE-negative BoHV1 vaccine [49]. Moreover, nasal vaccination is an interesting alternative for inducing specific antibody responses in female genital tract, both for convenience and because the outcome of vaginal vaccination might be dependent on the time point in the oestral cycle for vaccine administration [35].

Concerning infection control, such vaccination could bring several advantages. Indeed, the existence of antigenic cross-reactions between ruminant alphaherpesviruses related to BoHV-1 and their ability to cross the species barrier raise theoretical problems for the differential diagnosis and the detection of any other virus reservoir, both in regions and countries where BoHV-1 infection has been eradicated and in those where the control of IBR is currently or will be undertaken [2]. The use of such vaccination could reduce the circulation of CpHV1 in goats which would be therefore less involved in BoHV-1 misdiagnosis due to infection with a closely related alphaherpesvirus. Moreover, the development of new vaccines in order to protect minor species against infection causing economical and management problems meets a poor interest from the pharmaceutical industry. In this context, a classical inactivated vaccine inducing a good protection against CpHV-1 infection in goats was developed but was not licensed $[21,22]$. Consequently, it was required to investigate the capacity of an already licensed bovine vaccine to induce a cross-protection against a related virus infection in goats according to the principle of the cascade. The European Union has recently pointed out the requirements of medicinal veterinary products for minor uses and minor species, as goats for example [50]. The results obtained in this study clearly show that a bovine vaccine can be safely and efficiently used in goats.

\section{Conclusion}

Regarding the issue of ruminant alphaherpesvirus diagnosis, the economical constraints of the veterinary pharmaceutical industry and the well-being of animals, this study brings an expected tool for the CpHV-1 induced disease prevention. Indeed, the intranasal administration of a live attenuated gE-negative BoHV-1 vaccine protects goats clinically and virologically against $\mathrm{CpHV}-1$ genital infection which is the natural route of infection in goats. In addition, the current study emphasises the interest of studying intranasal vaccination approaches against genitally transmitted infections through the mucosal immune system. 


\section{Methods \\ Cells and viruses}

The Madin-Darby bovine kidney (MDBK) cell line (ATCC CCL22) was maintained in Dulbecco-Minimal Essential Medium (D-MEM) supplemented with 10\% of foetal bovine serum (FBS). The challenge CpHV-1 Ba-1 strain [51] was produced by infection of MDBK cells in D-MEM supplemented with $10 \%$ of FBS. At $72 \mathrm{~h}$ after infection, culture medium was removed and clarified by centrifugation at $1,500 \times \mathrm{g}$ for $20 \mathrm{~min}$. Supernatants were divided into aliquots, frozen at $-80^{\circ} \mathrm{C}$ and titrated by tissue culture infectious dose $50\left(\mathrm{TCID}_{50}\right)$ method on MDBK cells. The gE-negative BoHV-1 vaccine virus strain used for immunisation is the commercial vaccine Rispoval ${ }^{\circledR}$ IBR-marker vivum (Pfizer Animal Health). The BoHV-1 Iowa [52] and the CpHV-1 Ba-1 strains were used for serum neutralisation assays.

\section{Experimental design}

Nine dairy Alpine, Ionica, Maltese and Saanen crossbred goats, approximately 4-5 years of age, were used. All goats were originated from a CpHV-1 seronegative flock in Italy. Prior to inoculation, absence of antibodies against BoHV1 and CpHV-1 was confirmed by serum neutralisation assay. The goats were randomly divided in three groups of three goats. Each group was separated in different airspaces. Two groups were immunised intranasally by aerosolization twice three weeks apart as follows: group 1 received $2 \mathrm{ml}$ per nostril of virulent CpHV-1 Ba- 1 at a dose of $10^{5.25} \mathrm{TCID}_{50} / 50 \mu \mathrm{l}$, and group 2 received $2 \mathrm{ml}$ per nostril of gE-negative BoHV-1 vaccine at a dose of $10^{4.25}$ $\mathrm{TCID}_{50} / 50 \mu \mathrm{l}$. Group 3 served as negative control and was kept uninoculated before challenge. On day 42, all goats were challenged by the intravaginal route with $4 \mathrm{ml}$ of virulent CpHV-1 Ba-1 (10 $\left.6.25 \mathrm{TCID}_{50} / 50 \mu \mathrm{l}\right)$. All precautions were taken to avoid viral spread. Clothes and boots were changed before entering any stable. For handling, new gloves were used between groups. Clinical monitoring and all sampling procedures were carried out in a blind manner. Goats were clinically examined daily from day - 1 (before infection) up to day 21 following the challenge and rectal temperatures were also measured up to day 16 post-challenge. Clinical observations were carried out at approximately the same time everyday and by the same scientist throughout the study. Clinical monitoring included the following clinical signs: depression, anorexia, vaginal haemorrhage, vaginal discharge, pain, hyperemia of vulva and vagina, oedema of vulva and vagina, number of lesions in vulva and vagina. A clinical score from 0 to 2 was given for each clinical parameter except temperature. Scores quantifying the oedema of vulva and vagina were multiplied by 2 . Scores quantifying the number of lesions in vulva and vagina were multiplied by 3. Blood samples for serology were collected from the jugular vein of animals weekly during the whole experi- ment at days $0,7,14,21,28,35,42,49,56$ and 63 after the primary immunisation. Serums obtained after centrifugation were stored at $-20^{\circ} \mathrm{C}$ until analysis. Heparinised blood samples for buffy coat extraction, nasal and vaginal swabs were collected daily up to day 14 after first immunisation, up to day 14 after second immunisation, and during 14 days post-challenge, using one swab per animal, swabbing deeply into each nostril or vagina. The experiment was carried out following national and international guide for the care and use of experimental animals.

\section{Viral characterisation}

Samples were immersed in $1 \mathrm{ml}$ of D-MEM and centrifuged at $5,000 \times \mathrm{g}$ for $5 \mathrm{~min}$. The supernatant was then treated with a $10 \%$ antibiotics mixture $(5,000 \mathrm{UI} / \mathrm{ml}$ penicillin, 2,500 $\mu \mathrm{g} / \mathrm{ml}$ streptomycin, $10 \mu \mathrm{g} / \mathrm{ml}$ amphotericin) for $30 \mathrm{~min}$ at room temperature and titrated by the TCID $_{50}$ method on MDBK cells cultured in 96-well microtitre plates. The excess of samples was stored frozen at $80^{\circ} \mathrm{C}$. Cells were examined daily for cytopathic effect (CPE). The virus titre was expressed as TCID $_{50}$ per $50 \mu \mathrm{l}$ of secretion. Buffy coats were separated from blood by centrifugation in presence of lympholyte (Cedarlane, Canada). Sample preparation and polymerase chain reaction (PCR) were performed as previously described with minor modifications [13,53]. Viral DNA were prepared from supernatants of MDBK cell cultures infected with viruses isolated on days 1 and 4 after challenge [16]. Two $\mu \mathrm{g}$ of DNA were submitted to BstEII restriction analysis (New England Biolabs) and DNA fragments were separated in a $0.7 \%$ Tris Acetate EDTA gel for $22 \mathrm{~h}$ at $30 \mathrm{~V} / \mathrm{cm}$ and 500 $\mathrm{mA}$.

\section{Serological analysis}

Serial twofold dilutions of each serum were mixed with either 100 TICD $_{50}$ of BoHV-1 Iowa strain or 100 TICD $_{50}$ of CpHV-1 Ba-1 strain in 96-well microtitre plates. The plates were held for $90 \mathrm{~min}$ at room temperature and 20,000 MDBK cells were then added to each well. Analysis was done after three days of incubation at $37^{\circ} \mathrm{C}$ in presence of $5 \% \mathrm{CO}_{2}$. The titre of each serum was expressed as the highest serum dilution which neutralised the virus in 50\% of the wells [43]. The BoHV-1 gE blocking ELISA (Herdchek Anti-IBR gE, Idexx, Germany) was used following the manufacturer instructions. Serums were analysed in duplicate.

\section{Statistical analysis}

Statistical comparisons in the clinical, virological and serological data were performed in the form of mixed models for repeated measurements by SAS procedure (procedure MIXED) [54]. 


\section{Authors' contributions}

JT, MT, ETh and CB designed the experiments and analysed the data. JT, MT, MC and ETa performed the experiments. JT, MT, ETh and $\mathrm{CB}$ drafted the manuscript together. BM and FM helped to draft the manuscript. All authors read and approved the final manuscript.

\section{Acknowledgements}

The authors wish to thank Lorène Dams and Donato Narcisi for their excellent technical assistance and Frédéric Farnir for his helpful assistance for statistical analysis. This work was supported by Région Wallonne and Fonds Social Européen.

\section{References}

I. Thiry J, Keuser V, Muylkens B, Meurens F, Gogev S, Vanderplasschen $A$, Thiry E: Ruminant alphaherpesviruses related to bovine herpesvirus I. Vet Res 2006, 37:169-190.

2. Muylkens B, Thiry J, Kirten P, Schynts F, Thiry E: Bovine herpesvirus $I$ and infectious bovine rhinotracheitis. Vet Res 2007 , 38: $|8|-209$.

3. van Oirschot JT, Kaashoek MJ, Rijsewijk FA: Advances in the development and evaluation of bovine herpesvirus I vaccines. Vet Microbiol 1 996, 53:43-54.

4. Mars $M H$, De Jong MC, van Oirschot JT: A gE-negative bovine herpesvirus I vaccine strain is not re-excreted nor transmitted in an experimental cattle population after corticosteroid treatments. Vaccine 2000, I8:1975-1981.

5. Mars MH, De Jong MC, Franken P, van Oirschot JT: Efficacy of a live glycoprotein E-negative bovine herpesvirus I vaccine in cattle in the field. Vaccine 200I, 19:1924-1930.

6. Saito JK, Gribble DH, Berrios PE, Knight HD, Mc Kercher DG: A new herpesvirus isolate from goats: Preliminary report. Am J Vet Res 1974, 35:847-848.

7. Van der Lugt JJ, Randles JL: Systemic herpesvirus infection in neonatal goats. J S Afr Vet Assoc 1993, 64:169-171.

8. Tarigan S, Webb RF, Kirkland D: Caprine herpesvirus from balanoposthitis. Aust Vet J 1987, 64:32I

9. Grewal AS, Wells R: Vulvovaginitis of goats due to a herpesvirus. Aust Vet J 1986, 63:79-82.

10. Keuser V, Gogev S, Schynts F, Thiry E: Demonstration of generalized infection with caprine herpesvirus I diagnosed in an aborted caprine foetus by PCR. Vet Res Commun 2002 , 26:22I-226.

II. Tempesta M, Buonavoglia D, Sagazio P, Pratelli A, Buonavoglia C: Natural reactivation of caprine herpesvirus I in latently infected goats. Vet Rec 1998, I43:200.

12. Tempesta M, Pratelli A, Corrente M, Buonavoglia C: A preliminary study on the pathogenicity of a strain of caprine herpesvirusI. Comp Immunol Microbiol Infect Dis 1999, 22:137-143.

13. Tempesta M, Pratelli A, Greco G, Martella V, Buonavoglia C: Detection of caprine herpesvirus $I$ in sacral ganglia of latently infected goats by PCR. J Clin Microbiol I999, 37:1598-1599.

14. Guercio A, Greco G, Lanizzoto G, Di Marco V, Todaro M: Valutazione della diffusione di anticorpi anti Herpes Virus della capra in allevamenti caprini della Sicilia. Atti SIPAOC 1998, I 2: I 38-142.

15. Kao M, Leiskau T, Koptopoulos G, Papadopoulos O, Horner GW, Hyllseth B, et al.: Goat herpesvirus infections: a survey on specific antibodies in different countries. In Immunity to herpesvirus infections of domestic animals Edited by: Pastoret P-P, Thiry E, Saliki JT. Luxembourg: Report EUR 9737 EN; 1985:93-97.

16. Keuser V, Espejo-Serrano J, Schynts F, Georgin JP, Thiry E: Isolation of caprine herpesvirus type I in Spain. Vet $\operatorname{Rec} 2004$, I 54:395-399.

17. Koptopoulos G, Papanastasopoulou M, Papadopoulos O, Ludwig H: The epizootiology of caprine herpesvirus (BHV-6) infections in goat populations in Greece. Comp Immunol Microbiol Infect Dis 1988, I 1:199-205.

18. Muluneh A, Liebermann $\mathrm{H}$ : Occurrence of caprine herpesvirus (BHV-6) infection in goat population of the GDR. Arch Exp Veterinarmed 1990, 44(2):254-257.
19. Plebani GF, Engels M, Metzler AE, Wyler R: Caprines Herpesvirus in der Schweiz: Verbreitung Haüfigkeit und Latenz der Infektion. Schweiz Arch Tierheilkd 1983, I 25:395-4II.

20. Thiry J, Keuser V, Schynts F, Chartier C, Tempesta M, Espejo-Serrano J, Saegerman C, Thiry E: Evaluation de la prévalence sérologique de I'infection par l'herpèsvirus caprin I dans le sud-ouest de I'Europe. Epidémiol Santé Anim 2006, 49:55-8.

21. Tempesta M, Camero M, Greco G, Pratelli A, Martella V, Buonavoglia $C$ : A classical inactivated vaccine induces protection against caprine herpesvirus I infection in goats. Vaccine 200I, I 9:3860-3864.

22. Camero M, Bellacicco AL, Tarsitano E, Decaro N, Martella V, Tempesta $M$, Buonavoglia C: Intravaginal administration of an inactivated vaccine prevents lesions induced by caprine herpesvirus- I in goats. Vaccine 2007, 25: |658-|66I

23. Berrios PE, McKercher DG, Knight HD: Pathogenicity of a caprine herpesvirus. Am J Vet Res 1975, 36:1763-1769.

24. Mettler F, Engels M, Wild P, Bivetti A: Herpesvirus-Infektion bei Zicklein in der. Schweiz Arch Tierheilkd 1979, I 2 1:655-662.

25. Ackermann M, Metzler AE, McDonaugh H, Bruckner L, Muller HK Kihm U: Stellen nichtbovine paarhufer ein IBR-Virus-reservoir dar? I. BHV-I und CapHV-I infektions und reaktivierungsversuche an ziegen, virustyp-spezifitat der humoralen antikorper und charakterisierung der viralen antigene. Schweiz Arch Tierheilkd 1986, I 28:557-573.

26. Ros C, Belak S: Studies of genetic relationships between bovine, caprine, cervine, and rangiferine alphaherpesviruses and improved molecular methods for virus detection and identification. J Clin Microbiol 1999, 37: I247-1253.

27. Ros C, Belak S: Characterization of the glycoprotein $B$ gene from ruminant alphaherpesviruses. Virus Genes 2002, 24:99-105.

28. Ros C, Riquelme ME, Forslund KO, Belak S: Improved detection of five closely related ruminant alphaherpesviruses by specific amplification of viral genomic sequences. J Virol Methods 1999, 83:55-65.

29. Pirak M, Thiry E, Brochier B, Pastoret P-P: Infection expérimentale de la chèvre par le virus de la rhinotrachéite infectieuse bovine (bovine herpes virus I) et tentative de réactivation virale. Rec Méd Vét 1983, I 59: I I03-I 106.

30. Engels M, Palatini M, Metzler AE, Probst U, Kihm U, Ackermann M: Interactions of bovine and caprine herpesviruses with the natural and the foreign hosts. Vet Microbiol 1992, 33:69-78.

31. Six A, Banks M, Engels M, Bascunana CR, Ackermann M: Latency and reactivation of bovine herpesvirus I (BHV-I) in goats and of caprine herpesvirus I (CapHV-I) in calves. Arch Virol 200I, I46: I325-I335.

32. Thiry J, Tempesta M, Camero M, Tarsitano E, Bellacicco AL, Thiry E, Buonavoglia C: $A$ live attenuated glycoprotein $E$ negative bovine herpesvirus I vaccine induces a partial cross-protection against caprine herpesvirus I infection in goats. Vet Microbiol 2006, I I 3:303-308.

33. Davis SS: Nasal vaccines. Adv Drug Deliv Rev 200 I, 5 I:2 I-42.

34. Bergquist C, Johansson EL, Lagergard T, Holmgren J, Rudin A: Intranasal vaccination of humans with recombinant cholera toxin $B$ subunit induces systemic and local antibody responses in the upper respiratory tract and the vagina. Infect Immun 1997 , 65:2676-2684.

35. Johansson EL, Wassen L, Holmgren J, Jertborn M, Rudin A: Nasal and vaginal vaccinations have differential effects on antibody responses in vaginal and cervical secretions in humans. Infect Immun 200I, 69:748I-7486.

36. Brandtzaeg P, Baekkevold ES, Farstad IN, Jahnsen FL, Johansen FE, Nilsen EM, Yamanaka T: Regional specialization in the mucosal immune system: what happens in the microcompartments? Immunol Today 1999, 20:141-I5I.

37. Eriksson K, Quiding-Jarbrink M, Osek J, Moller A, Bjork S, Holmgren J, Czerkinsky C: Specific-antibody-secreting cells in the rectums and genital tracts of nonhuman primates following vaccination. Infect Immun 1998, 66:5889-5896.

38. Johansson EL, Rask C, Fredriksson M, Eriksson K, Czerkinsky C, Holmgren J: Antibodies and antibody-secreting cells in the female genital tract after vaginal or intranasal immunization with cholera toxin B subunit or conjugates. Infect Immun I998, 66:514-520. 
39. Perry LL, Feilzer K, Portis JL, Caldwell HD: Distinct homing pathways direct $T$ lymphocytes to the genital and intestinal mucosae in Chlamydia-infected mice. J Immunol 1998, 160:2905-29|4.

40. Johansson EL, Rudin A, Wassen L, Holmgren J: Distribution of lymphocytes and adhesion molecules in human cervix and vagina. Immunology 1999, 96:272-277.

4I. Johansen FE, Baekkevold ES, Carlsen HS, Farstad IN, Soler D, Brandtzaeg P: Regional induction of adhesion molecules and chemokine receptors explains disparate homing of human B cells to systemic and mucosal effector sites: dispersion from tonsils. Blood 2005, 106:593-600.

42. Meurens F, Whale J, Brownlie R, Dybvig T, Thompson DR, Gerdts V: Expression of mucosal chemokines TECK/CCL25 and MEC/ CCL28 during fetal development of the ovine mucosal immune system. Immunology 2007, I 20:544-555.

43. Lemaire M, Schynts F, Meyer G, Georgin JP, Baranowski E, Gabriel A, Ros C, Belak S, Thiry E: Latency and reactivation of a glycoprotein $E$ negative bovine herpesvirus type I vaccine: influence of virus load and effect of specific maternal antibodies. Vaccine 200I, 19:4795-4804.

44. Thiry E, Meurens F, Muylkens B, McVoy M, Gogev S, Thiry J, Vanderplasschen A, Schynts $F$ : Recombination in alphaherpesviruses. Rev Med Virol 2005, I 5:89-103.

45. Pagamjav O, Sakata T, Matsumura T, Yamaguchi T, Fukushi H: Natural recombinant between equine herpesviruses $I$ and 4 in the ICP4 gene. Microbiol Immunol 2005, 49:167-I79.

46. Meurens F, Keil GM, Muylkens B, Gogev S, Schynts F, Negro S, Wiggers L, Thiry E: Interspecific recombination between two ruminant alphaherpesviruses, bovine herpesviruses $I$ and 5. J Virol 2004, 78:9828-9836.

47. Tempesta M, Pratelli A, Normanno G, Camero M, Buonavoglia D, Greco G, Buonavoglia C: Experimental intravaginal infection of goats with caprine herpesvirus I. J Vet Med B Infect Dis Vet Public Health 2000, 47:197-201.

48. Tempesta M, Greco G, Pratelli A, Buonavoglia D, Camero M, Martella V, Buonavoglia C: Reactivation of caprine herpesvirus I in experimentally infected goats. Vet $\operatorname{Rec} 2002$, 150:116-117.

49. Howell DC: Power considerations in terms of sample size. Statistical Methods for Psychology. Duxbury Fourth edition. 1997:226.

50. Committee for Veterinary Medicinal Products: Position paper regarding availability of products for minor uses and minor species (MUMS). European Medicine Agency. Luxembourg:EMEA/ CVMP/477/03/final; 2004:I-I3.

5I. Buonavoglia C, Tempesta M, Cavalli A, Voigt V, Buonavoglia D, Conserva $A$, Corrente $M$ : Reactivation of caprine herpesvirus I in latently infected goats. Comp Immunol Microbiol Infect Dis 1996, | 9:275-28|.

52. Miller JM, van der Maaten MJ: Reproductive tract lesions in heifers after intrauterine inoculation with infectious bovine rhinotracheitis virus. Am J Vet Res 1984, 45:790-794.

53. Vilcek S: Detection of the bovine herpesvirus-I (BHV-I) genome by PCR. J Virol Methods 1993, 41:245-247.

54. Littell RC, Henry PR, Ammerman CB: Statistical analysis of repeated measures data using SAS procedures. J Anim Sci 1998, 76:|2|6-|23|
Publish with Biomed Central and every scientist can read your work free of charge

"BioMed Central will be the most significant development for disseminating the results of biomedical research in our lifetime. "

Sir Paul Nurse, Cancer Research UK

Your research papers will be:

- available free of charge to the entire biomedical community

- peer reviewed and published immediately upon acceptance

- cited in PubMed and archived on PubMed Central

- yours - you keep the copyright
BioMedcentral 